Artigos

Luciane Pandini Simiano'

\title{
Transver o mundo: um olhar sobre o lugar dos bebês no espaço da creche
}

Resumo: $O$ presente texto tem por foco o processo de constituição do espaço da creche em um lugar dos bebês. Busca-se (re)conhecer os lugares constituídos pelos bebês, tomando-os como indicativos para pensar a prática pedagógica e o espaço da creche. Como recurso argumentativo, apresenta-se elementos de uma pesquisa de mestrado em educação, de orientação etnográfica, realizada em uma instituição pública no sul do estado de Santa Catarina. Foram sujeitos da investigação um grupo de 10 bebês e quatro professoras. Como resultado, a partir do diálogo com Benjamim (1986), Tuan (1983) e as diretrizes normativas, defende-se a importância do espaço, por que o espaço educa, expõe ideias, externaliza mensagens. Contudo, no processo de constituição social, psíquica, afetiva e cognitiva dos bebês, é necessário, ir além das materialidades, atentando para a ocupação, as relações e os sentidos estabelecidos entre os bebês e adultos. Pensar a constituição do lugar e assumi-la como possibilidade de (re)organizar a creche remete a uma zona estranha, incerta e fascinante. Um convite a inverter o olhar e pensar uma lógica que vê, pesquisa e narra a criança pequena, não como faltosa ou incapaz, mas como força, potência e possibilidade.

Palavras-chave: Educação Infantil; Espaço; Lugar; Creche; Bebê.

\section{Transver the world: a look at the place of babies in space of nursery}

Abstract: This work is focused on the creation process of the nursery space in a place of babies. The aim is to (re) know the places made up of the babies, taking them as indicative to think the pedagogical practice and the space of the nursery. As Argumentative feature, presents elements of a master's research in education, ethnographic orientation held in a public institution in the southern state of Santa Catarina. Research subjects were a group of 10 babies and four teachers. As a result, from the dialogue with Benjamin (1986), Tuan (1983) and the normative guidelines, advocates the importance of space, the space educates, exposes ideas, externalize messages. However, in the process of social constitution, mental, emotional and cognitive babies, it is necessary to go beyond the material issues, noting the occupation, relationships and directions established between babies and adults. Think the constitution of the place and take it as a possibility to (re) organize the nursery throws us into a strange, uncertain and fascinating area. A call to reverse the look and think a logic that sees research and tells the little child, not as faulty or unable, but as strength, power and possibility.

Keywords: Space; Place; Nursery, Baby.

I Doutora em Educação pela UFRGS. Mestre em Educação. Pedagoga. Atualmente é professora permanente do Programa de Pós-Graduação em Educação da Universidade do Sul de Santa Catarina- UNISUL. Endereço: Avenida Jose Acácio Moreira, 787 Bairro Dehon - Caixa Postal 370 - CEP 88704-900 - Tubarão SC, Brasil - Endereço eletrônico: lucianepandini@gmail.com 
O olho vê.

A memória revê.

A imaginação transvê.

É preciso transver o mundo

(BARROS, 2006)

É consensual, entre teóricos e pesquisadores de diferentes campos, a importância de um espaço educativo de qualidade para o desenvolvimento e constituição subjetiva das crianças. Tal questão, tem suscitado estudos e pesquisas que buscam compreender o papel de instituições educativas no cuidado e educação de crianças pequenas, evocando reflexões: Quais as funções de uma creche? O que esperamos desses espaços? Como valorizar e respeitar as diferentes formas de ser e estar no espaço de educação infantil? 'Tais perguntas são ainda mais prementes quando falamos de bebês, cuja presença interroga, causa questionamentos e inquietação. Estudos recentes demonstram a redutiva oferta de vagas para crianças de 0 a 3 anos na educação infantil, o descompasso entre as políticas e infraestrutura dos espaços, bem como as dificuldades para a organização desses espaços em função de práticas pedagógicas frágeis e incapazes de reconhecer e valorar as diferentes formas de ser e estar na creche (SIMIANO 2010).

A legislação educacional brasileira apresenta um conjunto de documentos1 que orientam padrões de infraestrutura para as instituições de educação infantil. Esses documentos se consolidam em importantes orientações que indicam o que seria um espaço de qualidade para as crianças. De acordo com as Diretrizes Curriculares Nacionais para a Educação Infantil:

As instituições de Educação Infantil devem tanto oferecer espaço limpo, seguro e voltado para garantir a saúde infantil quanto se organizar como ambientes acolhedores, desafiadores e inclusivos, plenos de interações, explorações e descobertas partilhadas com outras crianças e com o professor. Elas ainda devem criar contextos que articulem diferentes linguagens e que permitam a participação, expressão, criação, manifestação e consideração de seus interesses. (BRASIL, 2009, p.6)

Pode-se perceber neste documento uma preocupação para além dos pressupostos arquitetônicos e higienistas. Ele aponta para a criação de contextos que possibilitem a acolhida, o desafio, a exploração, a participação e expressão de crianças e adultos que partilham e comungam o mesmo espaço.

BRASIL (1996, 1998, 1998a, 1999, 2001, 2006, 2006a, 2009a,). 
O espaço (físico, projetado, planejado) não garante tais relações, porém potencializa a construção de um lugar para os bebês viverem sua infância em plenitude. O espaço pode agradar aos olhos dos adultos, mas, muitas vezes, pode carecer da personalidade dos bebês que o habitam. Há instituições que parecem limpas, ávidas e com estruturas modernas, porém sente-se falta de marcas pessoais, simbólicas e singulares do grupo que por elas é habitado.

A instituição de educação infantil pensada e projetada para ser espaço de educação e cuidado das crianças pode ou não se constituir em um lugar do/para os bebês. Pois a constituição do lugar esta relacionada a ocupação do espaço pelas crianças que ali habitam e lhe atribuem significado, legitimando a sua condição

Procurando contribuir com a construção de um outro olhar sobre o espaço das instituições de educação infantil, considera-se fundamental entende-lo para além da dimensão física que o compõe, mas também discuti-lo sob a perspectiva de lugar, pois esse é produto da experiência humana (TUAN, 1983).

O lugar possui um significado para além do sentido físico e geográfico. Constituí-se (ou não) a partir da relação afetiva que os sujeitos desenvolvem ao longo de sua vida na convivência com o espaço e com o outro.

É a dimensão humana que transforma o espaço em lugar. Nas relações, nos encontros, nas experiências efetivam-se a constituição dos lugares. Tal processo implica pensarmos bebês e adultos vivendo e convivendo juntos na creche. Seguindo essa perspectiva, pode-se afirmar que o lugar é um elemento determinante na constituição dos sujeitos. Acredita-se que o lugar na educação infantil não é apenas constituidor das crianças, mas também constituídos por essas e, nesse sentido, entende-se que é fundamental oportunizar que os bebês infrinjam suas marcas e estabeleçam sentidos a este lugar.

O presente texto foca essas questões, a partir de um exercício de pesquisa, busca-se (re) conhecer os lugares constituídos pelos bebês, tomando-os como indicativos para pensar a prática pedagógica e o espaço da creche.

Para tanto, o desafio que se coloca, é olhar para os bebês sob uma nova perspectiva, não os reconhecendo mais como "infans" "incapazes de falar", mas como sujeitos potentes, capazes, que precisam ser valorado. Nesse processo, uma escuta sensível e refinada é fundamental. Não apenas 
escuta de verbo, mas de diferentes linguagens para conseguirmos substituir o "monólogo" pelo “diálogo" com os bebês. É preciso compreendê-lo como "ser competente em sua inteireza, capaz de sofisticadas formas de comunicação, mesmo quando bebê, estabelecendo trocas sociais com coetâneos e adultos através de uma rede complexa de vínculos afetivos” (FARIA, 1994, p.213).

Nesse sentido, torna-se primordial transver. Transver significa ver além. Por meio da sensibilidade, atentar-se ao sutil e delicado movimento do espaço constituindo-se em lugar. Relações, ocupações, experiências. Nada é preestabelecido. Busca-se romper com a obviedade e estabelecer outras prioridades e importâncias. Trata-se de reeducar olhos e ouvidos para a sutileza e delicadeza que envolvem o cotidiano da creche.

\section{Percursos metodológicos da pesquisa}

Como recurso argumentativo, apresenta-se elementos de uma pesquisa de mestrado em educação, tendo como ponto de partida as seguintes questões: $\mathrm{O}$ que os lugares constituídos pelos bebês podem nos indicar sobre as práticas pedagógicas e a organização do espaço no atendimento a bebês em instituições educativas?

A pesquisa de orientação etnográfica foi realizada em uma instituição pública no sul do estado de Santa Catarina. O enfoque privilegiado de análise foi a sala do berçário I, habitada por um grupo de 10 bebês ( 5 meninas e 5 meninos) com idade entre 4 meses à 18 meses e quatro adultos, duas professoras e duas auxiliares.

Nessa investigação, o ato de ver e ouvir foram exercícios fundamentais. Enxergar além do que se vê. Ouvir para além da fala oral. Perceber relações que se fazem presentes por diversas formas de expressões comunicativas. Expressões estas que adquirem significados e sentidos através do outro. Compreender o choro, o olhar, as expressões faciais, os gestos, os movimentos partilhados na/pela relação dos bebês com outros bebês e adultos requer diferentes procedimentos metodológicos. Os instrumentos de coleta dos dados foram o diário de campo, enriquecido pela fotografia e filmagens.

Como estratégia de análise, destaca-se como critério organizador: os espaços mais procurados pelos bebês, o tempo de permanência, os tipos de ocupações e relações estabelecidas entre bebês e adultos. A partir do entrecruzamento dos textos/imagens categorizados, foi possível es- 
tabelecer eixos de análises que sustentam o caminho percorrido na pesquisa. Busca-se com eles, oferecer visibilidade ao sutil processo de constituição dos lugares, através das diferentes ocupações e, sobretudo, das interações entre espaços e sujeitos. A marca das análises é a sutileza de um olhar atento aos sinais dos bebês.

\section{Um olhar sobre o lugar dos bebês no espaço da creche}

\section{Um lugar de encontro com meus rastros e traços}

Sentir-se parte, marcar, deixar rastros é fundamental na constituição dos lugares. Reconhecer a sua identidade, imprimir a singularidade na creche possibilita aos bebês o sentido de pertencimento ao lugar. É preciso que eles se reconheçam, pois só assim, a creche se constituirá como um lugar parte de sua vida.

Na sala da creche pesquisada, não havia espaço para acolher e disponibilizar os objetos que as crianças traziam de casa. Todos os pertences, com exceção da chupeta e cheirinho, que eram pendurados em ganchos2, guardados em bolsas que as crianças traziam de casa. Essas bolsas localizavam-se na repartição abaixo da mesa que serve para alimentar e trocar as crianças. As mochilas, embora estivessem na altura dos bebês, não podiam ser manipuladas por eles, apenas pela professora. Nela estavam guardadas fraldas, roupas, sapatos, meias e perfumes para higiene pessoal dos bebês.

Durante a pesquisa, observou-se a procura e permanência dos bebês no espaço onde se localizavam os pertences que traziam de suas casas. Embora não fosse permitido aos bebês estarem próximos às suas bolsas, mochilas e sacolas, eles transvêm os limites e vão ao encontro de seus pertences diariamente, apropriam-se daquele espaço, e o constituindo em um lugar de privacidade, intimidade, aconchego.

No processo de ocupação e constituição do espaço das mochilas em lugar, os bebês estão a dizer que a creche precisa ser organizada de forma que respeite sua singularidade. Proporcionar a organização de um espaço que possibilite o acesso a seus pertences, auxilia a criança a se reconhecer como único e ao mesmo tempo, como alguém que partilha sua vida com um grupo de amigos, em um contexto diverso do familiar. Os objetos trazidos de casa ajudam a criança a formar e constituir "um ninho seguro", pois estabelecem vínculos entre a casa e a creche.

2 Estes objetos eram pendurados na altura dos adultos e entregue aos bebês nos momentos de choro, sono ou solicitação. 
Muitas vezes, os espaços coletivos de educação em função da padronização dos tempos, espaços e materiais não permitem aos seus usuários um encontro com sua singularidade. A "cultura escolar" em nome da coletividade tenta apagar tudo que é de marca singular das crianças, assemelhando-se, assim, à "cultura de vidro". Todas as crianças guardam as bolsas com seus pertences no mesmo espaço. Esses espaços são pensados apenas para armazenar, guardar e organizar de forma a facilitar para os adultos o cuidado e higiene do corpo dos bebês. Benjamim (1986) cita uma frase de um poema que nos ajuda a comprender sobre o que estamos falando : “Apaguem os rastros!", diz o estribilho do poema de Brecht Cartilhas para citadinos. Essa atitude remete a pensar, o quanto muitas vezes, os espaços coletivos de educação e cuidado destinado às crianças, tentam apagar suas marcas, seus rastros, fazendo destes espaços, espaços de vidro, pois são modelados à imagem da escola.

Os bebês sinalizam que precisam de tempo/espaço para estar com seus pertences reconhecendo-se nos objetos que representam a sua singularidade. Ao se apropriarem do espaço de guardar as bolsas, mochilas e sacolas, os bebês mostram que aquele era um lugar de segurança onde eles se reconheciam. Manifestam que é preciso pensar, planejar, organizar lugares onde o bebê se sinta seguro, acolhido, familiarizado.

\section{Um lugar na e para além da sala}

Os bebês desde cedo, circunscrevem sua presença no espaço e constroem determinados lugares. No contexto dessa pesquisa, a "cerquinha” se constituiu em um desses lugares. Embora esse lugar passasse de forma silenciosa e invisível aos olhos dos adultos que, por vezes, buscavam retirar os bebês com medo de eles se machucarem, a cerquinha se configurava em um lugar extremamente rico para os bebês.

Lugar de chegada. Encontro. Partilha. Um lugar de olhar e ser olhado. Observou-se várias situações nas quais a cerquinha da sala significava para os bebês convites para encontrar o outro. Sendo a creche um espaço privilegiado de convívio com adultos e crianças de diferentes idades, acredita-se ser importante organizar, pensar e disponibilizar esse espaço de forma que se possam potencializar encontros entre bebê-bebê, bebê-criança e bebê adulto.

Os bebês têm direito a espaços de uso coletivo, têm direito a viver para além da sala. $\mathrm{Na}$ 
pesquisa os bebês permanecem quase sempre na sala, sendo raras as vezes em que transitam por outro espaço da creche. Esse fato é justificado pelas profissionais por questões estruturais sob a alegação de que os bebês não podem ir para a área externa e utilizar o parque pelas suas condições fisicas. A referência de que eles são pequenos é utilizada como explicação para a não possibilidade de eles frequentarem o parque. Nessa concepção, os bebês só poderão estar em contato com o parque, o pátio e a área externa quando crescerem, quando estiverem prontos, completos e quando forem "capazes".

Barbosa (2010) que o parque é um espaço fundamental para o bebê, portanto, precisa ser pensado e organizado na medida das crianças. Além disso, as crianças pequenas precisam de contato diário com a luz do sol, ar fresco, e com a observação e interação com a natureza. Os bebês apontam isso. Quando eles transvêm o espaço, permanecendo na cerca e enxergando nela possibilidades de encontro com o outro e com tudo que o espaço externo oferece, eles "dizem" que precisam, que necessitam viver a vida para além de uma cerca que separa, divide, segmenta e limita seus encontros com a alteridade.

A cerquinha é um lugar de passagem, pausa, fronteira. Os bebês imprimem marcas, e, assim, expressam o desejo de encontro com o outro, com o sol, o ar fresco, a água, areia, com a vida que pulsa no espaço externo. Trata-se de interpretar os sinais dos bebês e pensar o espaço da creche como um lugar de interação com a vida que pulsa na e para além da sala.

\section{Um lugar de encontro com o outro bebê}

O olhar, o sorriso, a aproximação, o movimento o toque... Tantas são as formas de comunicação que marcam a vida na creche. Para conhecer o espaço e interagir com o outro, os bebês se utilizam de muitas linguagens. Observar, reconhecer e compreender estas formas de comunicação nos bebês significa valorizá-los como sujeitos capazes, competentes e que têm algo a nos dizer sobre eles.

Ao adentrar na creche pesquisada, foi possível observar que os bebês mantêm um tipo de comunicação sensível e sintonizada com seus pares. Observou-se várias situações nas quais o olhar significava um convite para se movimentar ao encontro do outro. A partir da manifestação dos bebês, pode-se perceber que eles gostam e necessitam estabelecer relações, compartilhar significados 
e sentidos com seus coetâneos.

Nos momentos em que a professora e a auxiliar estavam envolvidas nas ações pedagógicas de cuidado, na alimentação, na troca, no banho, no acalento, os bebês transitavam livremente pela sala, desfrutando assim, de uma grande parcela de tempo livre. No ato de deixar os bebês transitarem livremente pela sala, disponibilizar brinquedos à sua altura e possibilitar tempos longos para suas descobertas, a professora cria um contexto que incentiva e sustenta a interação entre eles, assumindo assim, um posicionamento de confiança na capacidade dos bebês de viverem outras relações além das estabelecidas com os adultos.

Barbosa (2010) define o tempo como um elemento fundamental para a especificidade que envolve a educação dos bebês. Nas palavras da autora, o bebê precisa $\square$ ter tempo para brincar, fazer a mesma torre muitas vezes, derrubar, reconstruir, derrubar novamente, isso permite aos bebês sedimentar suas experiências". (BARBOSA 2010 p.3). Nesse sentido, pode-se afirmar que o espaço e o tempo são categorias básicas e fundamentais para a constituição da creche em lugar. Lugar de estar, brincar e viver uma infância inteira desfrutando da companhia de seus pares.

\section{Um lugar de encontro com narrativa do adulto}

Na pesquisa observou-se, os bebês "dizendo" através das mais variadas formas que querem um lugar para ser, um lugar de rastros e traços, um lugar na e para além da cerca, um lugar para se relacionar e brincar sozinhos, acompanhados de outros bebês e dos adultos.

$\mathrm{Na}$ creche, os adultos são os responsáveis pela educação dos bebês. A eles cabe a tarefa de mediar a constituição subjetiva do bebê e sua inserção no mundo da cultura. No cotidiano da pesquisa, constatou-se como a presença do adulto/professor perpassa os lugares apontados pelos bebês. Em alguns momentos, essa presença se dava de forma marcante, decisiva e extremamente visível. Em outros, ela acontecia de forma sutil, silenciosa, discreta e indireta. Na criação de contextos materiais, temporais e sociais, lá estava a presença da professora permitindo, proibindo, incentivando e sustentando ou não as vivências, as significações.

Percebeu-se a presença da professora que conversava com os bebês, antecipando e significando as ações cotidianas. As manifestações das crianças pequenininhas precisam ser transformadas em palavras para ampliar seu universo simbólico. É na relação com os adultos, ouvindo suas 
palavras, que o bebê vai atribuindo sentido e significado ao mundo que o cerca. Traduzir as ações dos bebês em palavras, contar histórias, ler poemas, cantar músicas possibilitam a sua interação com a linguagem oral e com o encontro de narrativas.

A professora ao narrar a vida na creche, os fatos, os acontecimentos, está possibilitando aos bebês uma produção de sentidos e significados que influenciam a sua trajetória de vida.

\section{Palavras finais para este tempo de estudo}

Frente à importância da creche para a constituição dos sujeitos, aposta-se naquilo que os bebês dizem: a capacidade de transver, de reinventar, de ressignificar a materialidade dos espaços a eles destinados, constituindo novas formas, sentidos e lugares...

Considerando, que a educação coletiva dos bebês efetiva-se na materialidade de um espaço, considera-se fundamental que ele seja rico, diverso em materiais, brinquedos, mobiliário. O espaço potencializa a educação. Mas, é o olhar, a conversa, o toque, o sorriso, a brincadeira, as relações, as experiências que transformam o espaço da creche em lugar, ou seja, em lócus de sentido, de construção de identidades. Para tanto se aposta na importância dos espaços (físico, material), mas entendese que ele não é suficiente. É necessário que este espaço se constitua em lugar para os bebês que ali vivem grande parte de sua infância.

No processo de constituição social, psíquica, afetiva e cognitiva dos bebês, é necessário, ir além das materialidades, atentando para a ocupação, as relações e os sentidos estabelecidos entre os bebês e adultos. Um lugar de rastros e traços, um lugar de encontro com a natureza, um lugar para brincar e para o encontro com a narrativa do adulto... Esses foram os lugares constituídos e constitutivos dos bebês. Pensar a constituição do lugar e assumi-la como possibilidade de (re)organizar a creche remete a uma zona estranha, incerta e fascinante. Um convite a inverter o olhar e pensar uma lógica que vê, pesquisa e narra a criança pequena, não como faltosa ou incapaz, mas como força, potência e possibilidade. 


\section{Referências Bibliográficas}

BARBOSA, M. C. As especificidades da açáo pedagógica com os bebês. Disponível em:< portal.mec.gov.br/index.php?option=com_docman.>. Acesso em: 20 de setembro de 2010.

BARBOSA, M.C. Práticas cotidianas na educaçáo infantil - Bases para a reflexáo sobre as orientaçóes curriculares. Brasília: MEC, 2009. Disponível em: <htp:www.portal.mec. gov. br/dmdocuments/relat_seb_praticas_cotidianas.pdf>. Acesso em: 30 mar. 2010.

BARROS, M de . Memórias inventadas a segunda infância. São Paulo: Planeta, 2006.

BENJAMIN, W. Magia e técnica, arte e política. 2. ed. São Paulo: Brasiliense, 1986.

BRASIL. Congresso Nacional. Lei no 9.394/96, de 20 de dezembro de 1996. Estabelece as diretrizes e base da educação nacional. Brasília: Diário Oficial da União, 1996.

. Ministério da Educação e Cultura. Indicadores de Qualidade para a Educaçáo Infantil. Brasília: MEC/SEF/DEP/COED, 2006.

Ministério da Educação e do Desporto. Secretaria de Educação Fundamental. Subsídios para credenciamento e funcionamento de instituiçóes de Educaçáo Infantil. Brasília: MEC/SEF, 1998.

- Ministério da Educação. Conselho Nacional de Educação. Câmara de Educação Básica. Resoluçáo n ${ }^{\circ} 01$, de 07 de abril de 1999. Institui as diretrizes curriculares nacionais para a Educação Infantil. Brasília: Diário Oficial da União, 1999, Seção 1, p. 18.

Plano Nacional de Educaçáo. Rio de Janeiro: DP\&A, 2001.

. Ministério da Educação e do Desporto. Secretaria de Educação Fundamental. Parâmetros Básicos de Infra-estrutura para Instituiçóes de Educação Infantil. Brasília: MEC/SEF, 2006.

- Parâmetros básicos de infra-estrutura para instituiçóes de educaçáo infantil: Encarte 1. Brasília: MEC, SEB, 2006a.

Ministério da Educação. Conselho Nacional de Educação. Câmara de Educação Básica. Parecer $\mathrm{n}^{\circ}$ 04, de 06 de setembro de 2000. Parecer Normativo sobre as diretrizes operacionais para a Educação Infantil. Disponível em: <http://www.mec.gov.br/cne/pdf/ PCB004v03.pdf>. Acesso em: 20 mar. 2009a.

FARIA, A. L. G. Impressóes sobre as creches no norte da Itália: bambini si diventa. In: ROSEMBERG, F.; CAMPOS, M. M. (Org.). Creches e pré-escolas no Hemisfério Norte. São Paulo: Cortez e Fundação Carlos Chagas, 1994, cap. 8, p. 211-233.

SIMIANO, L. P. Meu quintal é maior que o mundo... Da configuração do espaço da creche à constituição de um lugar de bebês. Dissertação (Mestrado em Educação) Universidade do Sul de Santa Catarina, Tubarão, 2010.

TUAN, Y. Espaço e lugar: a perspectiva da experiência. São Paulo: Difel, 1983.

VASCONCELLOS, T. Criança do lugar e lugar de criança. Disponível em: <http://www. anped.org.br/reunioes/29ra/trabalhos/.../GT07-2482--Int.pdf>. Acesso em: 12 jul. 2014. 